\title{
Limited Sampling Strategy for the Estimation of Mycophenolic Acid and its Acyl Glucuronide Metabolite Area under the Concentration-Time Curve in Japanese Lung Transplant Recipients
}

\author{
Masaki Tanaka ${ }^{1}$, Masafumi Kikuchi ${ }^{1,2}$, Shinya Takasaki ${ }^{1}$, Tensei Hirasawa ${ }^{2}$, Kensuke Shigeta ${ }^{2}$, Aoi Noda ${ }^{1}$, Miki Akiba \\ ${ }^{3}$, Yasushi Matsuda ${ }^{4}$, Hisashi Oishi ${ }^{4}$, Tetsu Sado ${ }^{4}$, Masafumi Noda ${ }^{4}$, Yoshinori Okada ${ }^{3,4}$, Nariyasu Mano ${ }^{1,2}$, Hiroaki \\ Yamaguchi ${ }^{1,2, a}$ \\ ${ }^{1}$.Department of Pharmaceutical Sciences, Tohoku University Hospital, 1-1 Seiryo-machi, Aoba-ku, Sendai, Japan. \\ ${ }^{2}$.Faculty of Pharmaceutical Sciences, Tohoku University, 6-3 Aramaki-Aza-Aoba, Aoba-ku, Sendai, Japan. ${ }^{3}$ Department \\ of Organ Transplantation Center, Tohoku University Hospital, 1-1 Seiryo-machi, Aoba-ku, Sendai, Japan. ${ }^{4}$ Department \\ of Thoracic Surgery, Tohoku University Hospital, 1-1 Seiryo-machi, Aoba-ku, Sendai, Japan,
}

Received, April 9, 2019; Revised, May 30, 2019; Accepted, August 5, 2019; Published, August 5, 2019.

\begin{abstract}
Purpose: The dose of mycophenolate mofetil (MMF) used to prevent rejection after lung transplantation is often adjusted based on the 12-hour area under the concentration-time curve $\left(\mathrm{AUC}_{0-12}\right)$ of mycophenolic acid (MPA). A limited sampling strategy (LSS) is useful to define the pharmacokinetic (PK) profiles of MPA and mycophenolic acid acyl glucuronide (AcMPAG). Therefore, this study aimed to design a LSS based on multiple linear regression for estimating the $\mathrm{AUC}_{0-12}$ of MPA and AcMPAG at the minimum blood sampling points in Japanese lung transplant patients with concomitant tacrolimus. Methods: Forty-five lung transplantation recipients were enrolled in a PK study of MPA, mycophenolic acid glucuronide (MPAG), and AcMPAG. The plasma MPA, MPAG, and AcMPAG concentrations were determined just before and at $0.5,1,2,4,8$, and 12 hours after dosing. The $\mathrm{AUC}_{0-12}$ of MPA and AcMPAG was calculated using a linear trapezoidal rule from the plasma concentration of each blood sampling time. LSS was used to develop models for estimated AUC in the model group $(n=23)$ and was evaluated in the validation group $(n=22)$. Results: The best three time-point equation was $4.04+1.64 \cdot \mathrm{C}_{1}+3.08 \cdot \mathrm{C}_{4}+5.17 \cdot \mathrm{C}_{8}$ for MPA, and $-0.13+3.01 \cdot \mathrm{C}_{1}+$ $3.51 \cdot \mathrm{C}_{4}+5.74 \cdot \mathrm{C}_{8}$ for AcMPAG. The prediction errors (PE) and the absolute prediction errors (APE) were within the clinically acceptable $\pm 5 \%$ and $15 \%$ range, respectively (MPA: PE $=2.00 \%$, APE $=11.66 \%$, AcMPAG: $\mathrm{PE}=0.98 \%, \mathrm{APE}=14.69 \%$ ). The percentage of estimated $\mathrm{AUC}_{0-12}$ within $\pm 15 \%$ of the observed $\mathrm{AUC}_{0-12}$ was $77.27 \%$ for MPA and $81.82 \%$ for AcMPAG. Conclusion: LSS using three time-point $\left(\mathrm{C}_{1}, \mathrm{C}_{4}\right.$, and $\mathrm{C}_{8}$ ) provides the most reliable and accurate simultaneous estimation of the $\mathrm{AUC}_{0-12}$ of MPA and AcMPAG in Japanese lung transplant patients.
\end{abstract}

\section{INTRODUCTION}

Mycophenolate mofetil (MMF) is rapidly hydrolyzed in vivo to the immunosuppressant mycophenolic acid (MPA), which reversibly inhibits inosine 5'-monophosphate dehydrogenase, an enzyme involved in the de novo synthesis of guanosine in lymphocytes $(1,2)$. Subsequently, MPA is predominantly metabolized to a pharmacologically inactive mycophenolic acid glucuronide (MPAG) and pharmacologically active mycophenolic acid acyl glucuronide (AcMPAG) by uridine diphosphate glucuronosyltransferase (3). On the other hand, MPAG is hydrolyzed back to MPA during enterohepatic recirculation, and its contribution to the total MPA exposure is approximately $40 \%$ (4).

MMF is administered in combination with a calcineurin inhibitor, such as tacrolimus or cyclosporine, and steroid to reduce the risk of rejection after lung transplantation (5). Several studies have reported that the 12-hour area under the concentration-time curve $\left(\mathrm{AUC}_{0-12}\right)$ of MPA is a useful pharmacokinetic parameter for predicting clinical efficacy and rejection $(6,7)$. Therefore, the dose of MMF is often adjusted based on the $\mathrm{AUC}_{0-12}$ of MPA.

\footnotetext{
Corresponding Author: Hiroaki Yamaguchi, Ph.D. Department of Pharmaceutical Sciences, Tohoku University Hospital, 1-1 Seiryo-machi, Aoba-ku, Sendai, Japan. Email: hiroaki.yamaguchi@med.id.yamagata-u.ac.jp ${ }^{\text {PPresent address: }}$ Yamagata University Graduate School of Medical Science/Department of Pharmacy, Yamagata University Hospital, 2-2-2, Iida-nishi, Yamagata, 990-9585, Japan.
} 
Recently, Zegarska et al. have been reported that AcMPAG concentrations in liver transplant recipients is related to the development of bacterial infection (8). In addition, Yoshimura et al. have been reported that the cutoff values of AcMPAG AUC ${ }_{0-24}$ for successful gastrointestinal acute graft-versushost disease prevention in hematopoietic stem cell transplant patients were $15.6 \mu \mathrm{g} \cdot \mathrm{hr} / \mathrm{mL}$ (9). Accordingly, therapeutic drug monitoring (TDM) of AcMPAG is considered important in ensuring the safety and effectiveness of MMF treatment in both clinical practice and research.

The continuous measurement of MPA and AcMPAG $\mathrm{AUC}_{0-12}$ based on multiple blood sampling points increases the patient's burden. For this reason, a limited sampling strategy (LSS) estimating the $\mathrm{AUC}_{0-12}$ based on a limited number of blood samples is essential for defining the PK profiles of MPA and AcMPAG. However, LSS that simultaneously evaluates the $\mathrm{AUC}_{0-12}$ of MPA and AcMPAG has not been reported.

This study aimed to design a LSS based on multiple linear regression for estimating the $\mathrm{AUC}_{0-12}$ of MPA and AcMPAG at the minimum blood sampling points in Japanese lung transplant patients with concomitant tacrolimus.

\section{MATERIALS AND METHODS}

\section{Patients}

This study was a single-center prospective study, was performed in Tohoku University Hospital from December 2016 to December 2017. The inclusion criteria were as follows: age $\geq 18$ years, after lung transplantation, use of MMF, and the ability and willingness to provide written informed consent. We did not set the exclusion criteria. The chronic diseases that lead to lung transplantation were lymphangioleiomyomatosis $(\mathrm{n}=16)$, interstitial pneumonia $(n=9)$, pulmonary hypertension $(n=7)$, bronchiectasis $(n=3)$, Eisenmenger syndrome $(n=3)$, pulmonary emphysema $(\mathrm{n}=2)$, diffuse panbronchiolitis $(n=2)$, cystic fibrosis $(n=1)$, and other pulmonary disease $(n=2)$. Forty-five transplant recipients were enrolled in a study investigating the pharmacokinetics of MPA, MPAG, and AcMPAG. This study protocol was approved by the Ethics Committee of Tohoku University Graduate School of Medicine (approval number: 2017-1-096). All patients were provided written informed consent.

\section{Immunosuppression regimen}

All patients received MMF, tacrolimus, and prednisolone as a basic triple immunosuppressive regimen in lung transplantation. MMF (CellCept ${ }^{\mathbb{B}}$; Chugai Pharmaceutical Co., Ltd., Tokyo, Japan) was administered by intubation from the day 2 after surgery, and it was switched to oral administration after tube was withdrawn. MMF was administered at $1000 \mathrm{mg} /$ day (body weight $<60 \mathrm{~kg}$ ) or $1500 \mathrm{mg} /$ day (body weight $\geq 60 \mathrm{~kg}$ ). The dose of MMF was adjusted so that the white blood cell count was 4000 or more. The dose was reduced if abdominal symptoms were present. Tacrolimus was adjusted to maintain a target concentration of 10 to $14 \mathrm{ng} / \mathrm{mL}$ within 6 months after transplantation, 9 to $13 \mathrm{ng} / \mathrm{mL}$ from 7 months to 1 year after transplantation, and 8 to $10 \mathrm{ng} / \mathrm{mL}$ afterward. Prednisolone was orally administered at $1 \mathrm{mg} / \mathrm{kg} /$ day after transplantation, and then tapered to a fixed maintenance dose of 5 $\mathrm{mg} /$ day by 6 months after transplantation.

\section{Assay of plasma MPA, MPAG, and AcMPAG concentrations}

MPA was purchased from Sigma-Aldrich (Tokyo, Japan), MPAG, AcMPAG, and MPA- ${ }^{2} \mathrm{H}_{3}$ (internal standard, IS) were from Toronto Research Chemicals (Toronto, Ontario, Canada). The plasma concentrations of MPA, MPAG, and AcMPAG was measured as previously described, with modifications $(10,11)$. Briefly, blood collected in heparin tubes was centrifuged at $1580 \times g$ for 10 minutes to separate the plasma. To stabilize AcMPAG, $10 \%$ acetic acid was added to $20 \mu \mathrm{L}$ per milliliter of plasma (11). Thirty-microliters of acidified plasma were mixed with $30 \mu \mathrm{L}$ of $1 \mu \mathrm{g} / \mathrm{mL}$ MPA- $-{ }^{2} \mathrm{H}_{3}$ dissolved in acetonitrile for use as an internal standard substance. In addition, $120 \mu \mathrm{L}$ of acetonitrile was added to denatured proteins and centrifuged at $15,000 \times g$ for 5 minutes. To prepare a sample for injection, $200 \mu \mathrm{L}$ of water was added to $100 \mu \mathrm{L}$ of this supernatant. For LC/ESI-MS/MS analysis, a LCMS-8050 triple quadrupole mass spectrometer coupled with a Nexera X2 UHPLC system (Shimadzu, Kyoto, Japan) was used. Nexera X2 UHPLC consisted of a vacuum degasser, two solvent delivery systems, an autosampler, and a column oven. Chromatographic separation was achieved using an Inertsil C8-3 column $(150 \times 2.1$ $\mathrm{mm}$ i.d., $3 \mu \mathrm{m}$, GL Sciences, Tokyo, Japan), which was maintained at $40^{\circ} \mathrm{C}$. The mobile phase consisted of solution $\mathrm{A}(0.1 \%$ formic acid in water $)$ and solution B $(0.1 \%$ formic acid in acetonitrile), which formed the following gradient: $45 \% \mathrm{~B}(0-2 \mathrm{~min})$; $45-70 \%$ B (2-5.4 min); 45\% B (5.4-6.5 min). The flow rate of the mobile phase was $0.3 \mathrm{~mL} / \mathrm{min}$. The 
LCMS-8050 was equipped with an electrospray ionization source operating in positive and negative ion detection mode. During selected reaction monitoring, the $\mathrm{m} / \mathrm{z}$ transitions $321.25 \rightarrow 303.25$, $495.15 \rightarrow 319.15, \quad 495.15 \rightarrow 319.15, \quad$ and $324.30 \rightarrow 306.30$ monitored MPA, MPAG, AcMPAG, and $\mathrm{MPA}^{-}{ }^{2} \mathrm{H}_{3}$, respectively. Three controls $(0.15,1.5,15 \mu \mathrm{g} / \mathrm{mL}$ for MPA, $1.2,12,120$ $\mu \mathrm{g} / \mathrm{mL}$ for $\mathrm{MPAG}$, and $0.03,0.3,3 \mu \mathrm{g} / \mathrm{mL}$ for AcMPAG, respectively) were used for quality control. Linearity was achieved with a correlation coefficient $\left(R^{2}\right)>0.995(0.1$ to $20 \mu \mathrm{g} / \mathrm{mL}$ for MPA, 0.8 to $160 \mu \mathrm{g} / \mathrm{mL}$ for MPAG, and 0.02 to $4 \mu \mathrm{g} / \mathrm{mL}$ for AcMPAG, respectively). The intra- and inter-day precisions were less than $14.2 \%$, and accuracy was $\pm 11.2 \%$.

\section{Pharmacokinetic analyses and $\mathrm{AUC}_{0-12}$ calculation}

The plasma concentrations of MPA, MPAG, and AcMPAG were determined just prior to dosing and $0.5,1,2,4,8$, and 12 hours after administration. The pharmacokinetic parameters and $\mathrm{AUC}_{0-12}$ of MPA, MPAG, and AcMPAG were analyzed by a noncompartmental model from the plasma concentration of each blood sampling time (Phoenix WinNonlin software Version 7.0 [Certara USA, Inc., Princeton, NJ, USA]).

\section{STATISTICAL ANALYSIS}

According to the previous report (12-14), the patients were randomly assigned to two groups at a 1: 1 ratio: the model group $(n=23)$ and the validation group $(\mathrm{n}=22)$. An $\mathrm{AUC}_{0-12}$ prediction formula was derived using multiple regression analysis with the model group $\mathrm{AUC}_{0-12}$ as a dependent variable and the plasma concentration at each blood sampling time as an explanatory variable. A maximum of three concentrations were used for the clinically convenient limited sampling strategy. In the validation group, the predictive performance of the LSS was analyzed with linear regression, correlation coefficient $(r)$, prediction error $(\mathrm{PE})(\%)$, absolute prediction error (APE) (\%), and the percentage of estimated AUC within $\pm 15 \%$ of the observed AUC as previous reported (15). The two error parameters were calculated using the following equations:

$$
\begin{gathered}
\operatorname{PE}(\%)=\frac{100}{\mathrm{n}} \cdot \frac{\sum\left(\mathrm{AUC}_{\text {predicted }}-\mathrm{AUC}_{\text {observed }}\right)}{\mathrm{AUC}_{\text {observed }}} \\
\operatorname{APE}(\%)=\frac{100}{\mathrm{n}} \cdot \frac{\sum\left(\mid \mathrm{AUC}_{\text {predicted }}-\mathrm{AUC}_{\text {observed }} \mathrm{l}\right)}{\mathrm{AUC}_{\text {observed }}}
\end{gathered}
$$

where $\mathrm{n}$ is the number of patients. According to the previous report (15-17), the acceptable percentage limits of PE and APE were defined to be $\pm 5 \%$ and $15 \%$, respectively. The Bland-Altman test was used to evaluate the agreement between the observed and estimated AUC, and the fixed range was defined as the mean $\pm 1.96 \mathrm{SD}$. Continuous variables (expressed as mean $\pm \mathrm{SD}$ ) were compared using the $t$ test, and categorical variables were compared using the Fisher's exact test. The significance level was set at $P<0.05$. We used SAS Version 9.4 (SAS Institute Inc., Cary, NC, USA) for statistical analysis.

\section{RESULTS}

Forty-five patients (18 males and 27 females) were included in this study and the patients were randomly assigned to two groups at a 1: 1 ratio: the model group $(\mathrm{n}=23)$ and the validation group $(\mathrm{n}=$ 22). Patient characteristics are summarized in Table 1. The mean age was $44.4 \pm 11.6$ years and the mean body weight was $51.5 \pm 11.6 \mathrm{~kg}$. There were no significant differences in sex, laboratory test results, concomitant medications affecting the pharmacokinetics of MPA (proton pump inhibitor, magnesium oxide, ciprofloxacin), MMF dose, pharmacokinetic parameters of MPA and metabolites, tacrolimus dose, or the post-transplant period between the model group and the validation group.

The mean plasma concentration-time profiles of MPA, MPAG, and AcMPAG in the model and validation groups are shown in Figure 1. These curves followed a similar tendency, whereby the peak was reached after 2 hours for MPA and 4 hours for MPAG and AcMPAG. Among these compounds, MPA and AcMPAG are related to clinical outcomes; therefore, we focused on both MPA and AcMPAG. 
Table 1. Baseline characteristics of patients

\begin{tabular}{|c|c|c|c|c|}
\hline & $\begin{array}{l}\text { All Patients } \\
(\mathrm{n}=45)\end{array}$ & $\begin{array}{l}\text { Model Group } \\
(\mathrm{n}=23)\end{array}$ & $\begin{array}{l}\text { Validation Group } \\
(\mathrm{n}=22)\end{array}$ & $P$ \\
\hline Age (yr) & $44.4 \pm 11.6$ & $45.5 \pm 11.6$ & $43.1 \pm 11.8$ & 0.497 \\
\hline Sex (Male/Female) & $18 / 27$ & $8 / 15$ & $10 / 12$ & 0.236 \\
\hline Body weight (kg) & $51.5 \pm 11.6$ & $53.2 \pm 12.6$ & $49.6 \pm 10.3$ & 0.298 \\
\hline Serum creatinine $(\mathrm{mg} / \mathrm{dL})$ & $1.01 \pm 0.34$ & $1.03 \pm 0.40$ & $0.99 \pm 0.27$ & 0.684 \\
\hline Blood urea nitrogen (mg/dL) & $19.4 \pm 7.0$ & $19.3 \pm 7.8$ & $19.5 \pm 6.2$ & 0.927 \\
\hline $\begin{array}{l}\text { Estimated glomerular filtration rate } \\
\left(\mathrm{mL} / \mathrm{min} / 1.73 \mathrm{~m}^{2}\right)\end{array}$ & $60.9 \pm 23.2$ & $58.5 \pm 20.5$ & $63.4 \pm 26.0$ & 0.487 \\
\hline$\gamma$-Glutamyltransferase $(\mathrm{U} / \mathrm{L})$ & $31.3 \pm 18.3$ & $28.9 \pm 21.8$ & $33.8 \pm 13.8$ & 0.371 \\
\hline Alanine aminotransferase (U/L) & $12.9 \pm 7.1$ & $11.3 \pm 5.0$ & $14.6 \pm 8.6$ & 0.128 \\
\hline Aspartate aminotransferase (U/L) & $16.6 \pm 4.4$ & $15.7 \pm 2.9$ & $17.6 \pm 5.4$ & 0.137 \\
\hline Total protein (mg/dL) & $6.29 \pm 0.51$ & $6.27 \pm 0.55$ & $6.31 \pm 0.48$ & 0.779 \\
\hline Serum albumin (mg/dL) & $3.96 \pm 0.36$ & $3.97 \pm 0.39$ & $3.95 \pm 0.33$ & 0.891 \\
\hline White blood cell count $\left(\times 10^{3} / \mu \mathrm{L}\right)$ & $6.38 \pm 2.14$ & $6.23 \pm 2.17$ & $6.54 \pm 2.16$ & 0.633 \\
\hline Neutrophil count $\left(\times 10^{3} / \mu \mathrm{L}\right)$ & $4.30 \pm 1.86$ & $4.16 \pm 1.89$ & $4.45 \pm 1.86$ & 0.602 \\
\hline \multicolumn{5}{|l|}{ Concomitant medications } \\
\hline Proton pump inhibitor & 43 & 22 & 21 & 1.000 \\
\hline Magnesium oxide & 11 & 5 & 6 & 1.000 \\
\hline Ciprofloxacin & 1 & 1 & 0 & 1.000 \\
\hline MMF dose (range) (mg/day) & $\begin{array}{l}789 \pm 402 \\
(250-1500)\end{array}$ & $\begin{array}{c}826 \pm 415 \\
(250-1500)\end{array}$ & $\begin{array}{c}750 \pm 393 \\
(250-1500)\end{array}$ & 0.532 \\
\hline MPA AUC $0-12(\mu \mathrm{g} \cdot \mathrm{hr} / \mathrm{mL})$ & $32.2 \pm 11.8$ & $32.8 \pm 13.0$ & $31.5 \pm 10.6$ & 0.713 \\
\hline $\begin{array}{l}\text { Dose-normalized MPA AUC }{ }_{0-12} \\
{[(\mu \mathrm{g} \cdot \mathrm{hr} / \mathrm{mL}) / \mathrm{g}]}\end{array}$ & $51.8 \pm 35.6$ & $43.1 \pm 13.4$ & $60.9 \pm 48.5$ & 0.098 \\
\hline MPA $T_{\max }(h r)$ & $2.53 \pm 2.00$ & $2.09 \pm 1.90$ & $3.00 \pm 2.05$ & 0.128 \\
\hline MPA $C_{\max }(\mu \mathrm{g} / \mathrm{mL})$ & $6.98 \pm 3.50$ & $7.03 \pm 3.76$ & $6.94 \pm 3.29$ & 0.931 \\
\hline MPAG AUC ${ }_{0-12}(\mu \mathrm{g} \cdot \mathrm{hr} / \mathrm{mL})$ & $404 \pm 288$ & $457 \pm 349$ & $350 \pm 199$ & 0.210 \\
\hline $\begin{array}{l}\text { Dose-normalized MPAG AUC } 0-12 \\
{[(\mu \mathrm{g} \cdot \mathrm{hr} / \mathrm{mL}) / \mathrm{g}]}\end{array}$ & $617 \pm 516$ & $556 \pm 259$ & $681 \pm 692$ & 0.423 \\
\hline MPAG $\mathrm{T}_{\max }(\mathrm{hr})$ & $3.53 \pm 1.87$ & $3.13 \pm 1.29$ & $3.95 \pm 2.28$ & 0.147 \\
\hline MPAG $C_{\max }(\mu \mathrm{g} / \mathrm{mL})$ & $49.7 \pm 34.0$ & $53.4 \pm 39.3$ & $45.9 \pm 27.8$ & 0.469 \\
\hline AcMPAG AUC ${ }_{0-12}(\mu \mathrm{g} \cdot \mathrm{hr} / \mathrm{mL})$ & $3.23 \pm 2.60$ & $3.32 \pm 2.56$ & $3.14 \pm 2.69$ & 0.819 \\
\hline $\begin{array}{l}\text { Dose-normalized AcMPAG AUC }{ }_{0-12} \\
{[(\mu \mathrm{g} \cdot \mathrm{hr} / \mathrm{mL}) / \mathrm{g}]}\end{array}$ & $5.78 \pm 8.41$ & $4.39 \pm 3.34$ & $7.23 \pm 11.50$ & 0.262 \\
\hline AcMPAG $\mathrm{T}_{\max }(\mathrm{hr})$ & $3.41 \pm 2.21$ & $3.11 \pm 1.66$ & $3.73 \pm 2.68$ & 0.355 \\
\hline AcMPAG $C_{\max }(\mu \mathrm{g} / \mathrm{mL})$ & $0.55 \pm 0.39$ & $0.55 \pm 0.39$ & $0.54 \pm 0.41$ & 0.987 \\
\hline Tacrolimus dose (mg/day) & $2.81 \pm 1.74$ & $3.04 \pm 1.63$ & $2.56 \pm 1.85$ & 0.356 \\
\hline $\begin{array}{l}\text { Tacrolimus trough concentration } \\
(\mathrm{ng} / \mathrm{mL})\end{array}$ & $9.12 \pm 2.07$ & $9.41 \pm 2.35$ & $8.82 \pm 1.73$ & 0.345 \\
\hline Post-transplant period (day) & $1460 \pm 934$ & $1404 \pm 983$ & $1518 \pm 899$ & 0.686 \\
\hline
\end{tabular}

Continuous variables (expressed as mean $\pm \mathrm{SD}$ ) were compared using the $t$ test, and categorical variables were compared using the Fisher's exact test. MMF: mycophenolate mofetil, MPA: mycophenolic acid, MPAG: mycophenolic acid glucuronide, AcMPAG: mycophenolic acid acyl glucuronide. 

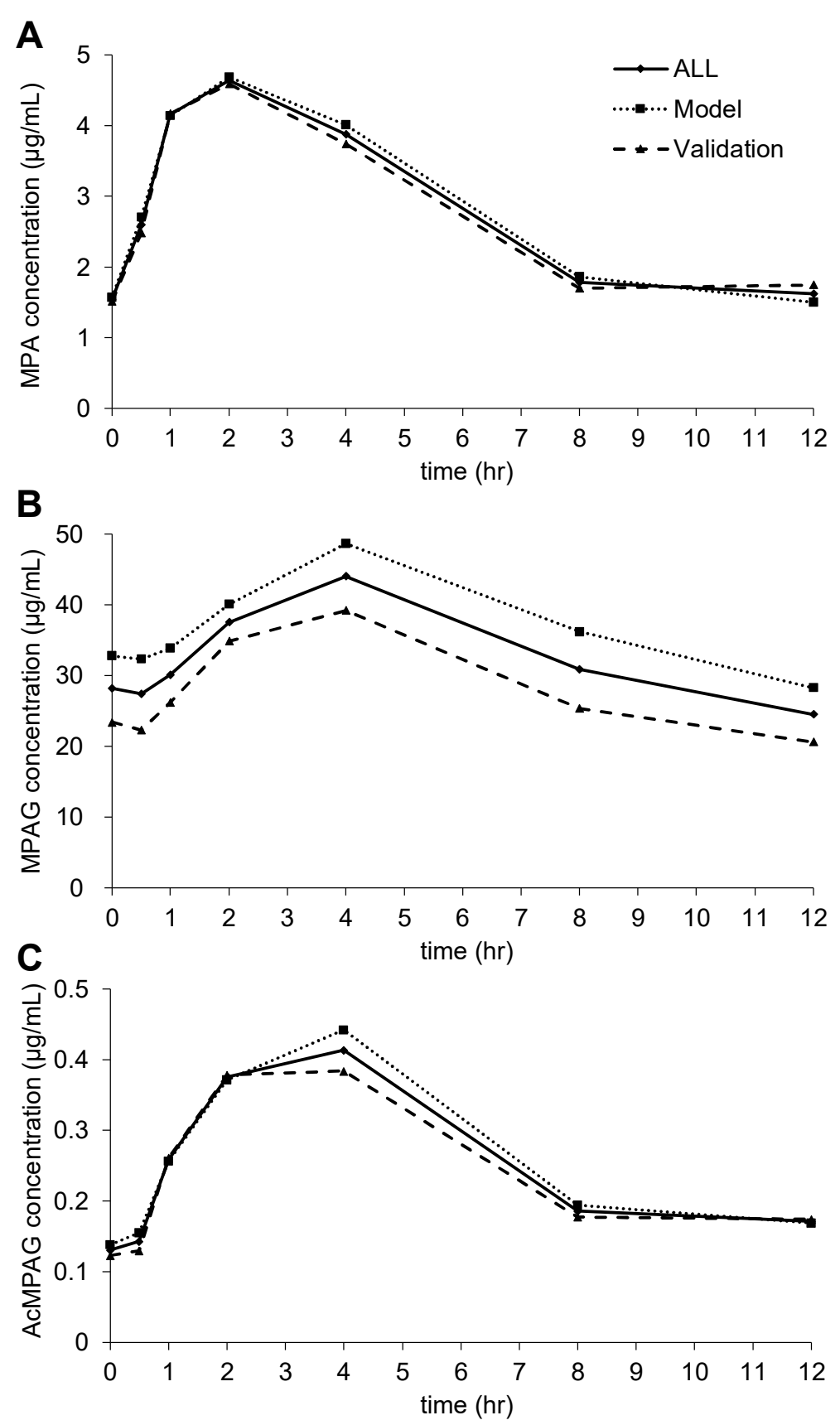

Figure 1. Mycophenolic acid (MPA) (A), mycophenolic acid glucuronide (MPAG) (B), and mycophenolic acid acyl glucuronide (AcMPAG) (C) concentration-time profiles.

Multiple linear regression analyses of the MPA and AcMPAG $\mathrm{AUC}_{0-12}$ are shown in Table 2. The highest correlation coefficient between MPA AUC $\mathrm{A}_{0}$ 12 and plasma MPA concentrations was at $\mathrm{C}_{1}, \mathrm{C}_{4}$, and $\mathrm{C}_{8}$ for three time points (MPA $\mathrm{AUC}_{0-12}=4.04+$ $\left.1.64 \cdot \mathrm{C}_{1}+3.08 \cdot \mathrm{C}_{4}+5.17 \cdot \mathrm{C}_{8}, r=0.923, P<0.001\right)$.
Conversely, the highest correlation coefficient between AcMPAG $\mathrm{AUC}_{0-12}$ and plasma AcMPAG concentrations was obtained at three time points, $\mathrm{C}_{2}$, $\mathrm{C}_{4}$, and $\mathrm{C}_{12}$ (AcMPAG AUC $\mathrm{AU}_{0-12}=0.28+1.96 \cdot \mathrm{C}_{2}+$ $\left.3.44 \cdot \mathrm{C}_{4}+4.64 \cdot \mathrm{C}_{12}, r=0.990, P<0.001\right)$ 
Table 2. Predictive performance of three concentration limited sampling strategies developed for MPA and AcMPAG

\begin{tabular}{|c|c|c|c|c|c|c|}
\hline $\begin{array}{l}\text { Sampling } \\
\text { time }(\mathrm{hr})\end{array}$ & Equation & $r$ & $P$ & $\begin{array}{l}\mathrm{PE} \\
(\%)\end{array}$ & $\begin{array}{l}\text { APE } \\
(\%)\end{array}$ & $\begin{array}{c}\text { Within } \pm \\
15 \%{ }^{*}\end{array}$ \\
\hline \multicolumn{7}{|c|}{ MPA } \\
\hline $1,4,8$ & $4.04+1.64 \cdot C_{1}+3.08 \cdot C_{4}+5.17 \cdot C_{8}$ & 0.923 & $<0.001$ & 2.00 & 11.66 & 77.27 \\
\hline $2,4,8$ & $4.42+1.64 \cdot C_{2}+2.86 \cdot C_{4}+4.96 \cdot C_{8}$ & 0.895 & $<0.001$ & 0.82 & 11.27 & 68.18 \\
\hline $2,4,12$ & $6.40+1.70 \cdot C_{2}+2.92 \cdot C_{4}+4.48 \cdot C_{12}$ & 0.885 & $<0.001$ & 6.61 & 14.86 & 59.09 \\
\hline $1,4,12$ & $5.32+1.76 \cdot C_{1}+2.98 \cdot C_{4}+5.49 \cdot C_{12}$ & 0.843 & $<0.001$ & 8.47 & 17.43 & 54.55 \\
\hline $0.5,2,12$ & $10.82+0.68 \cdot \mathrm{C}_{0.5}+1.37 \cdot \mathrm{C}_{2}+9.12 \cdot \mathrm{C}_{12}$ & 0.831 & $<0.001$ & 12.20 & 18.17 & 54.55 \\
\hline $0,2,12$ & $9.54+3.65 \cdot C_{0}+1.45 \cdot C_{2}+7.17 \cdot C_{12}$ & 0.829 & $<0.001$ & 11.29 & 18.16 & 45.45 \\
\hline $0,2,4$ & $4.91+3.06 \cdot \mathrm{C}_{0}+2.03 \cdot \mathrm{C}_{2}+3.39 \cdot \mathrm{C}_{4}$ & 0.820 & $<0.001$ & 2.48 & 16.35 & 63.64 \\
\hline $0.5,4,12$ & $11.97+0.46 \cdot \mathrm{C}_{0.5}+2.14 \cdot \mathrm{C}_{4}+7.34 \cdot \mathrm{C}_{12}$ & 0.809 & $<0.001$ & 11.75 & 20.36 & 50.00 \\
\hline $0.5,2,4$ & $5.12+0.68 \cdot \mathrm{C}_{0.5}+2.11 \cdot \mathrm{C}_{2}+3.98 \cdot \mathrm{C}_{4}$ & 0.796 & $<0.001$ & 1.36 & 17.61 & 54.55 \\
\hline $0,4,12$ & $12.82+0.86 \cdot \mathrm{C}_{0}+2.05 \cdot \mathrm{C}_{4}+6.93 \cdot \mathrm{C}_{12}$ & 0.788 & $<0.001$ & 12.32 & 21.11 & 45.45 \\
\hline $1,2,12$ & $11.35+0.8 \cdot C_{1}+0.97 \cdot C_{2}+9.08 \cdot C_{12}$ & 0.785 & $<0.001$ & 13.87 & 20.06 & 54.55 \\
\hline \multicolumn{7}{|c|}{ AcMPAG } \\
\hline $2,4,12$ & $0.28+1.96 \cdot \mathrm{C}_{2}+3.44 \cdot \mathrm{C}_{4}+4.64 \cdot \mathrm{C}_{12}$ & 0.990 & $<0.001$ & 7.38 & 14.84 & 68.18 \\
\hline $1,4,12$ & $0.12+2.43 \cdot \mathrm{C}_{1}+3.89 \cdot \mathrm{C}_{4}+5.03 \cdot \mathrm{C}_{12}$ & 0.976 & $<0.001$ & 6.89 & 17.50 & 59.09 \\
\hline $0,4,12$ & $0.26+1.70 \cdot \mathrm{C}_{0}+3.62 \cdot \mathrm{C}_{4}+7.19 \cdot \mathrm{C}_{12}$ & 0.975 & $<0.001$ & 2.47 & 22.10 & 45.45 \\
\hline $0.5,4,12$ & $0.23+0.98 \cdot \mathrm{C}_{0.5}+3.86 \cdot \mathrm{C}_{4}+7.23 \cdot \mathrm{C}_{12}$ & 0.975 & $<0.001$ & 1.42 & 20.55 & 45.45 \\
\hline $2,4,8$ & $0.09+2.24 \cdot \mathrm{C}_{2}+3.07 \cdot \mathrm{C}_{4}+5.27 \cdot \mathrm{C}_{8}$ & 0.974 & $<0.001$ & 1.53 & 12.81 & 72.73 \\
\hline $0,2,4$ & $-0.12+5.84 \cdot C_{0}+2.76 \cdot C_{2}+3.60 \cdot C_{4}$ & 0.969 & $<0.001$ & 0.81 & 19.64 & 59.09 \\
\hline $2,8,12$ & $0.59+2.13 \cdot \mathrm{C}_{2}+6.51 \cdot \mathrm{C}_{8}+3.92 \cdot \mathrm{C}_{12}$ & 0.966 & $<0.001$ & 14.84 & 25.23 & 45.45 \\
\hline $4,8,12$ & $0.24+3.15 \cdot \mathrm{C}_{4}+4.12 \cdot \mathrm{C}_{8}+5.21 \cdot \mathrm{C}_{12}$ & 0.965 & $<0.001$ & 0.50 & 21.61 & 45.45 \\
\hline $0.5,2,4$ & $-0.12+2.53 \cdot \mathrm{C}_{0.5}+2.80 \cdot \mathrm{C}_{2}+4.53 \cdot \mathrm{C}_{4}$ & 0.959 & $<0.001$ & -0.31 & 21.45 & 63.64 \\
\hline $1,2,4$ & $0.06+1.59 \cdot \mathrm{C}_{1}+2.08 \cdot \mathrm{C}_{2}+4.67 \cdot \mathrm{C}_{4}$ & 0.956 & $<0.001$ & 6.42 & 25.97 & 59.09 \\
\hline $1,4,8$ & $-0.13+3.01 \cdot C_{1}+3.51 \cdot C_{4}+5.74 \cdot C_{8}$ & 0.955 & $<0.001$ & 0.96 & 14.87 & 77.27 \\
\hline
\end{tabular}

*Percentage of estimated AUC within $\pm 15 \%$ of the observed AUC. MPA: mycophenolic acid, AcMPAG: mycophenolic acid acyl glucuronide, PE: prediction error, APE: absolute prediction error.

Considering the combination of the three timepoint models, it was two models $\left(\mathrm{C}_{1}, \mathrm{C}_{4}, \mathrm{C}_{8}\right.$ and $\mathrm{C}_{2}$, $\mathrm{C}_{4}, \mathrm{C}_{8}$ ) that PE and APE were clinically acceptable within $\pm 5 \%$ and $15 \%$, respectively.

Moreover, the percentage of estimated $\mathrm{AUC}_{0-12}$ within $\pm 15 \%$ of the observed $\mathrm{AUC}_{0-12}$ was higher in model $\left(\mathrm{C}_{1}, \mathrm{C}_{4}, \mathrm{C}_{8}\right)$ than in model $\left(\mathrm{C}_{2}, \mathrm{C}_{4}, \mathrm{C}_{8}\right)$. Therefore, the LSS of MPA and AcMPAG with the most convenient and conventional sampling times were for $\mathrm{C}_{1}, \mathrm{C}_{4}$, and $\mathrm{C}_{8}$ (MPA $\mathrm{AUC}_{0-12}=4.04+$ $1.64 \cdot \mathrm{C}_{1}+3.08 \cdot \mathrm{C}_{4}+5.17 \cdot \mathrm{C}_{8}, \mathrm{AcMPAG} \mathrm{AUC}_{0-12}=-$ $\left.0.13+3.01 \cdot \mathrm{C}_{1}+3.51 \cdot \mathrm{C}_{4}+5.74 \cdot \mathrm{C}_{8}\right)$. In the 
validation group, the $\mathrm{PE}$ and $\mathrm{APE}$ of this models were within the clinically acceptable range (MPA: $\mathrm{PE}=2.00 \%, \mathrm{APE}=11.66 \%$, AcMPAG: $\mathrm{PE}=0.98 \%$, APE $=14.69 \%)$. The percentage of estimated AUC within $\pm 15 \%$ of the observed AUC was $77.27 \%$ for MPA and $81.82 \%$ for AcMPAG. The correlation between the measured and estimated $\mathrm{AUC}_{0-12}$ of MPA and AcMPAG for LSS in Figure 2 also suggested a good estimation (MPA: $r=0.923, P<$ 0.001 , AcMPAG: $r=0.955, P<0.001)$. The BlandAltman analysis revealed a mean bias of $2.00 \%$ for MPA AUC ${ }_{0-12}$ and $0.98 \%$ for AcMPAG. Only three plotted differences exceeded the fixed range of the mean $\pm 1.96 \mathrm{SD}$ in the estimation using $\mathrm{C}_{1}, \mathrm{C}_{4}$, and $\mathrm{C}_{8}$ (Figure 3).

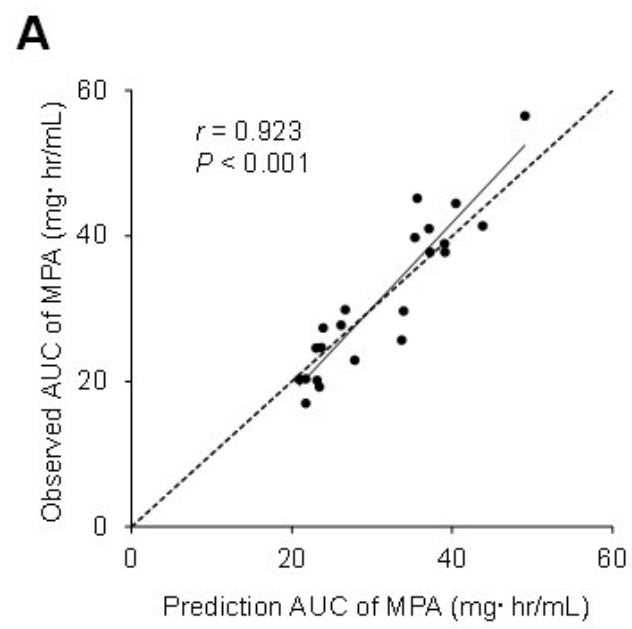

\section{B}

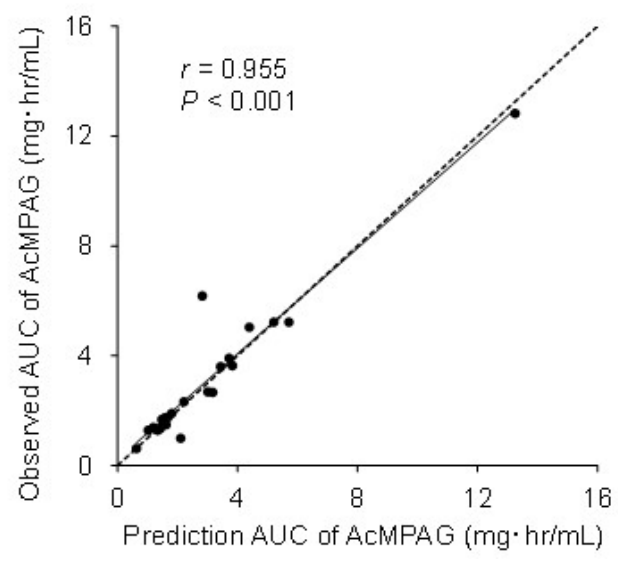

Figure 2. Correlation between the measured and estimated $\mathrm{AUC}_{0-12}$ of MPA (A) and AcMPAG (B) using three sampling points $\left(\mathrm{C}_{1}, \mathrm{C}_{4}\right.$, and $\left.\mathrm{C}_{8}\right)$ for limited sampling strategies (MPA AUC ${ }_{0-12}=4.04+1.64 \cdot \mathrm{C}_{1}+$ $3.08 \cdot \mathrm{C}_{4}+5.17 \cdot \mathrm{C}_{8}, \mathrm{AcMPAG} \mathrm{AUC} 0-12=-0.13+3.01 \cdot \mathrm{C}_{1}$ $\left.+3.51 \cdot \mathrm{C}_{4}+5.74 \cdot \mathrm{C}_{8}\right)$.

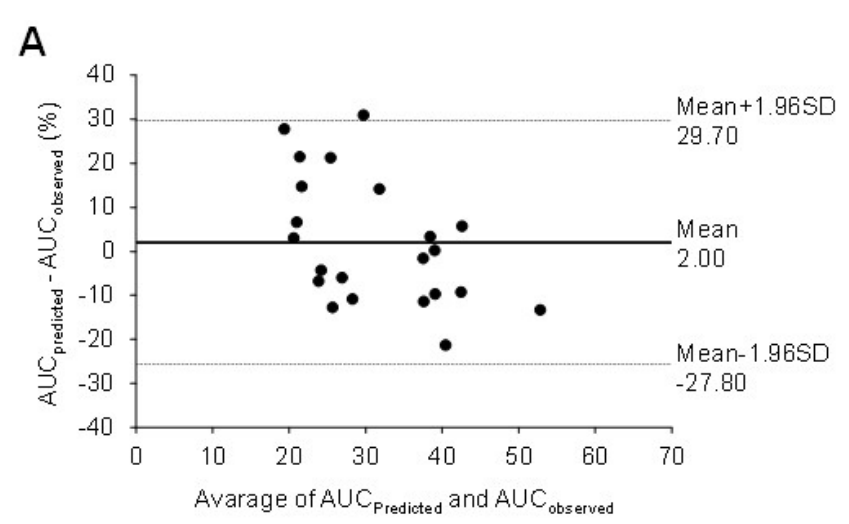

B

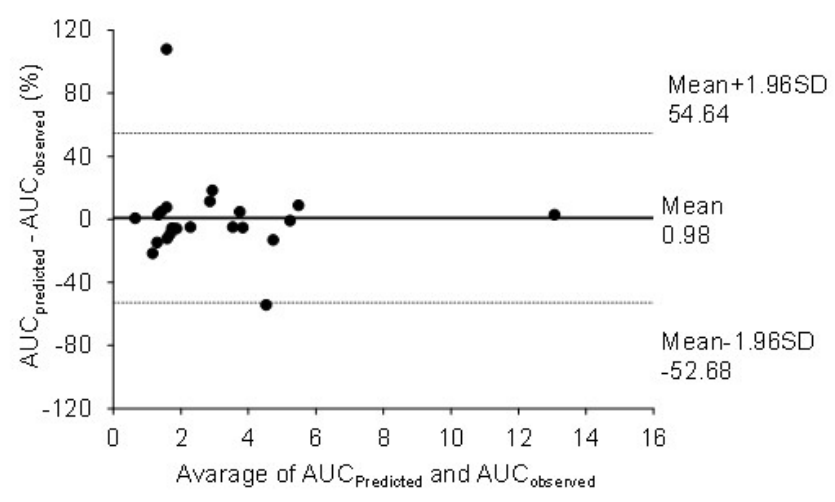

Figure 3. Bland-Altman plot for the validation group of MPA (A) and AcMPAG (B) using the three time-point $\left(\mathrm{C}_{1}, \mathrm{C}_{4}\right.$, and $\left.\mathrm{C}_{8}\right)$ equation (MPA AUC $\mathrm{M-12}=4.04+$ $1.64 \cdot \mathrm{C}_{1}+3.08 \cdot \mathrm{C}_{4}+5.17 \cdot \mathrm{C}_{8}$, AcMPAG AUC $\mathrm{Al}_{0-12}=-0.13$ $\left.+3.01 \cdot \mathrm{C}_{1}+3.51 \cdot \mathrm{C}_{4}+5.74 \cdot \mathrm{C}_{8}\right)$. The line represents the mean bias and the dashed lines represent \pm 1.96 standard deviation (SD) of the mean bias.

When the trough concentration was included at blood sampling points within 4 hours, the blood sampling points with the greatest correlations were $\left(\mathrm{C}_{0}, \mathrm{C}_{2}, \mathrm{C}_{4}\right)\left(\mathrm{MPA} \mathrm{AUC}_{0-12}=4.91+3.06 \cdot \mathrm{C}_{0}+\right.$ $2.03 \cdot \mathrm{C}_{2}+3.39 \cdot \mathrm{C}_{4}, r=0.820, P<0.001, \mathrm{AcMPAG}$ $\mathrm{AUC}_{0-12}=-0.12+5.84 \cdot \mathrm{C}_{0}+2.76 \cdot \mathrm{C}_{2}+3.60 \cdot \mathrm{C}_{4} r=$ $0.955, P<0.001)$. The PE of this models was within the clinically acceptable range (MPA: 2.43\%, AcMPAG: 0.98\%), but the APE was exceeded 15\% (MPA: 16.32\%, AcMPAG: 19.87\%).

\section{DISCUSSION}

In this study, we showed that the $\mathrm{AUC}_{0-12}$ can be predicted with high accuracy by LSS using plasma MPA and AcMPAG concentrations following MMF administration in Japanese lung transplantation 
patients.

Both immunoassays and chromatographic methods are available for therapeutic drug monitoring of MPA. Although immunoassays are widely used in clinical laboratories due to ease of adopting such methods on automated analyzers, immunoassay such as a particle-enhanced turbidimetric inhibition immunoassay (PETINIA) shows cross-reactivity with AcMPAG. In fact, we have revealed an average positive bias of $26.3 \%$ in the PETINIA compared to that with LC-MS/MS in lung transplant patients (18). Furthermore, MPAG and AcMPAG can only be measured by LC-MS/MS. Therefore, plasma MPA, MPAG, and AcMPAG concentrations were quantified by LC-MS/MS in this study.

The pharmacokinetics of MPA and its metabolites are reported to be affected by the administration of concomitant drugs, and differ between lung and heart transplant patients (19-23). Therefore, the development of the LSS of MPA and AcMPAG should consider concomitant medication as well as the transplanted organ. Proton pump inhibitor or magnesium oxide reduces the solubility of MMF and decreases the drug exposure of mycophenolic acid $(24,25)$. In addition, ciprofloxacin reduces plasma MPA concentration because of noncompetitive inhibition of deconjugation of MPAG by intestinal $\beta$-glucuronidase (26). However, there were no significant differences in baseline characteristics of patients including concomitant drugs between the model group and the validation group. The mean MPA, MPAG, and AcMPAG concentration-time profiles of all patients, the model group, and the validation group followed the same trend.

The primary enzymes involved in MPA glucuronidation are uridine-diphosphate glucuronosyltransferase (UGT) 1A9, 2B7, 1A8, and $1 \mathrm{~A} 7$ (27). In addition, UGT1A9 -275T $>\mathrm{A}$ and $2152 \mathrm{C}>\mathrm{T}$ polymorphism that affect the pharmacokinetics of MPA have been reported in Caucasians (28). Nevertheless, maximum MPA concentration, time to reach the maximum MPA concentration, AUC ratio MPAG/MPA, and AUC ratio AcMPAG/MPA were similar to those previously reported (29).

Considering the correlation coefficient, PE, APE, and the percentage of estimated AUC within $\pm 15 \%$ of the observed AUC, the most convenient and conventional sampling times were obtained with the three time-point $\left(\mathrm{C}_{1}, \mathrm{C}_{4}\right.$, and $\left.\mathrm{C}_{8}\right)$ equations. Therefore, the three time-point $\left(\mathrm{C}_{1}, \mathrm{C}_{4}\right.$, and $\left.\mathrm{C}_{8}\right)$ equations were developed (MPA $\mathrm{AUC}_{0-12}=4.04+$
$1.64 \cdot \mathrm{C}_{1}+3.08 \cdot \mathrm{C}_{4}+5.17 \cdot \mathrm{C}_{8}, r=0.923, P<0.001$, AcMPAG AUC $0-12=-0.13+3.01 \cdot \mathrm{C}_{1}+3.51 \cdot \mathrm{C}_{4}+$ 5.74. $\left.\mathrm{C}_{8}, r=0.955, P<0.001\right)$. Compared to previous reports $(30,31)$, the three time-point equations developed in this study have a relatively better predictive performance (MPA: $\mathrm{PE}=2.00 \%$, $\mathrm{APE}=11.66 \%$, AcMPAG: $\mathrm{PE}=0.98 \%$, APE $=$ $14.69 \%$ ). Moreover, about $80 \%$ of the estimated AUC was within $\pm 15 \%$ of the observed AUC.

LSS in lung transplantation patients was previously reported by Ting et al (12). Those authors developed LSS by two time points $\left(\mathrm{C}_{0}\right.$ and $\left.\mathrm{C}_{2}\right)$ in the same number of patients for cyclosporine and tacrolimus in combination; however, the correlation coefficient of the two time points $\left(\mathrm{C}_{0}\right.$ and $\left.\mathrm{C}_{2}\right)$ was 0.699 in this study, and a good correlation was not observed (data not shown). Cyclosporine inhibits the biliary transporter ATP-binding cassette, subfamily $\mathrm{C}$, member 2 (ABCC2), resulting in reduced enterohepatic re-circulation of MPAG/MPA (18-20), but tacrolimus has no such effect. For this reason, pharmacokinetics of MPA, MPAG, and AcMPAG are significantly different between cyclosporine and tacrolimus (29). All patients received tacrolimus, suggesting that the influence of $\mathrm{C}_{8}$ or $\mathrm{C}_{12}$ derived from the enterohepatic re-circulation of MPAG/MPA was greater than that reported by Ting et al (2006). Tacrolimus is used more commonly after lung transplantation due to its effect at reducing the risk of bronchiolitis obliterans syndrome and low levels of rejection as well as control of persistent rejection $(32,33)$. Therefore, the formula used here to estimate $\mathrm{AUC}_{0-12}$ may be useful to adjust the dose of MMF in patients treated with tacrolimus after lung transplantation.

Blood sampling 8 hours after MMF administration is not practical because it restrains outpatients' activities for a long time. The same multiple regression method was performed with the variables within 2 hours post-dose $\left(\mathrm{C}_{0}, \mathrm{C}_{0.5}, \mathrm{C}_{1}\right.$, and $\mathrm{C}_{2}$ ), but the correlation coefficient of the three time points was not sufficient (data not shown). When the trough concentration is included at blood sampling points within 4 hours, there was a good correlation with the three time-point equation $\left(\mathrm{C}_{0}, \mathrm{C}_{2}\right.$, and $\left.\mathrm{C}_{4}\right)$ (MPA: $r=0.820, P<0.001$, AcMPAG: $r=0.969, P$ $<0.001)$. However, the APE exceeded $15 \%$, and should therefore be carefully evaluated. Recently, we developed a LC-MS/MS method for the quantification of MPA, MPAG, and AcMPAG in dried blood spot samples (10). The dried blood spot method makes it possible to collect blood sample 8 hours after MMF administration without restraining 
the outpatients. Therefore, application of the dried blood spot method to outpatients may permit TDM using three-point blood sampling $\left(\mathrm{C}_{1}, \mathrm{C}_{4}\right.$, and $\left.\mathrm{C}_{8}\right)$.

This study has some limitations that should be considered. All cases were Japanese lung transplant patients taking tacrolimus, and it is not evaluated by other races. In additon, no collected datapoint between 4 and 8 hours after MMF intake potentially related to the enterohepatic re-circulation of MPAG/MPA was not collected. Moreover, the PK profiles were obtained at approximately 4 years post-transplant, and genetic polymorphism for MPA and AcMPAG metabolism were not analyzed. We also need to consider using population PK modeling to make AUC estimation based on limited sampling more robust and enhance its prediction performance.

\section{CONCLUSION}

We established a formula to estimate the $\mathrm{AUC}_{0-12}$ of MPA and AcMPAG by LSS in Japanese lung transplant patients with concomitant tacrolimus. The best three time-point equation was $4.04+1.64 \cdot \mathrm{C}_{1}+$ $3.08 \cdot \mathrm{C}_{4}+5.17 \cdot \mathrm{C}_{8}$ for MPA, and $-0.13+3.01 \cdot \mathrm{C}_{1}+$ $3.51 \cdot \mathrm{C}_{4}+5.74 \cdot \mathrm{C}_{8}$ for AcMPAG. It could be a useful tool to utilized for clinical practice and research.

\section{CONFLICT OF INTEREST}

No conflicts of interest to disclose.

\section{ACKNOWLEDGMENTS}

This study was supported by a Grant-in-Aid from the Japan Research Foundation for Clinical Pharmacology (HY).

\section{ABBREVIATIONS}

MMF: mycophenolate mofetil

MPA: mycophenolic acid

MPAG: mycophenolic acid glucuronide

AcMPAG: mycophenolic acid acyl glucuronide

$\mathrm{AUC}_{0-12}$ : 12-hour area under the concentration-time curve

TDM: therapeutic drug monitoring

LSS: limited sampling strategy

PE: prediction error

APE: absolute prediction error

UGT: uridine-diphosphate glucuronosyltransferase

\section{REFERENCES}

1. Ransom JT. Mechanism of action of mycophenolate mofetil. Ther Drug Monit 1995; 17: 681-684.

2. Sintchak MD, Fleming MA, Futer O, Raybuck SA, Chambers SP, Caron PR, Murcko MA, Wilson KP. Structure and mechanism of inosine monophosphate dehydrogenase in complex with the immunosuppressant mycophenolic acid. Cell 1996; 85: 921-930.

3. Shipkova M, Armstrong VW, Wieland E, Niedmann PD, Schütz E, Brenner-Weiss G, Voihsel M, Braun F, Oellerich M. Identification of glucoside and carboxyl-linked glucuronide conjugates of mycophenolic acid in plasma of transplant recipients treated with mycophenolate mofetil. Br J Pharmacol 1999; 126: 1075-82.

4. Bullingham RE, Nicholls AJ, Kamm BR. Clinical pharmacokinetics of mycophenolate mofetil. Clin Pharmacokinet 1998; 34: 429-55.

5. Zuckermann A, Reichenspurner H, Birsan T, Treede H, Deviatko E, Reichart B, Klepetko W. Cyclosporine A versus tacrolimus in combination with mycophenolate mofetil and steroids as primary immunosuppression after lung transplantation: oneyear results of a 2-center prospective randomized trial. J Thorac Cardiovasc Surg 2003; 125: 891-900.

6. Kuypers DR, Le Meur Y, Cantarovich M, Tredger MJ, Tett SE, Cattaneo D, Tönshoff B, Holt DW, Chapman J, Gelder Tv; Transplantation Society (TTS) Consensus Group on TDM of MPA. Consensus report on therapeutic drug monitoring of mycophenolic acid in solid organ transplantation. Clin J Am Soc Nephrol 2010; 5: 341-358.

7. Gaston RS, Kaplan B, Shah T, Cibrik D, Shaw LM, Angelis M, Mulgaonkar S, Meier-Kriesche HU, Patel D, Bloom RD. Fixed- or controlled-dose mycophenolate mofetil with standard- or reduceddose calcineurin inhibitors: the Opticept trial. Am J Transplant 2009; 9: 1607-1619.

8. Zegarska J, Hryniewiecka E, Żochowska D, Tszyrsznic W, Jaźwiec R, Borowiec A, Pawłowska E, Dadlez M, Pączek L. Mycophenolic Acid Metabolites Acyl-Glucuronide and Glucoside Affect the Occurrence of Infectious Complications and Bone Marrow Dysfunction in Liver Transplant Recipients. Ann Transplant 2015; 20: 483-492.

9. Yoshimura K, Yano I, Yamamoto $\mathrm{T}$, Kondo $\mathrm{T}$, Kawanishi M, Isomoto Y, Yonezawa A, TakaoriKondo A, Matsubara K. Pharmacokinetic and Pharmacodynamic Markers of Mycophenolic Acid Associated with Effective Prophylaxis for Acute Graft-Versus-Host Disease and Neutrophil 
Engraftment in Cord Blood Transplant Patients. Biol Blood Marrow Transplant 2018; 24: 1441-1448.

10. Iboshi H, Yamaguchi H, Suzuki H, Kikuchi M, Tanaka M, Takasaki S, Takahashi A, Maekawa M, Shimada M, Matsuda Y, Okada Y, Mano N. Development of a Liquid Chromatography-Tandem Mass Spectrometric Method for Quantification of Mycophenolic Acid and Its Glucuronides in Dried Blood Spot Samples. Ther Drug Monit 2017; 39: 648-653.

11. Kawanishi M, Yano I, Yoshimura K, Yamamoto T, Hashi S, Masuda S, Kondo T, Takaori-Kondo A, Matsubara K. Sensitive and validated LC-MS/MS methods to evaluate mycophenolic acid pharmacokinetics and pharmacodynamics in hematopoietic stem cell transplant patients. Biomed Chromatogr 2015; 29: 1309-1316.

12. Ting LS, Partovi N, Levy RD, Riggs KW, Ensom $\mathrm{MH}$. Limited sampling strategy for predicting area under the concentration-time curve of mycophenolic acid in adult lung transplant recipients. Pharmacotherapy 2006, 26: 1232-1240.

13. Jia Y, Peng B, Li L, Wang J, Wang X, Qi G, Rong R, Wang L, Qiu J, Xu M, Zhu T. Estimation of mycophenolic acid area under the curve with limited-sampling strategy in chinese renal transplant recipients receiving enteric-coated mycophenolate sodium. Ther Drug Monit 2017; 39: 29-36.

14. David OJ, Johnston A. Limited sampling strategies for estimating cyclosporin area under the concentration-time curve: review of current algorithms. Ther Drug Monit 2001; 23: 100-14.

15. Sheiner LB, Beal SL. Some suggestions for measuring predictive performance. Pharmacokinet Biopharm 1981; 9: 503-512.

16. Meier-Kriesche HU, Kaplan B, Brannan P, Kahan BD, Portman RJ. A limited sampling strategy for the estimation of eight-hour neoral areas under the curve in renal transplantation. Ther Drug Monit 1998; 20: 401-407.

17. Niioka T, Miura M, Kagaya H, Saito M, Numakura

K, Habuchi T, Satoh S. A limited sampling strategy to estimate the area under the concentration-time curve of tacrolimus

modified-release once-daily preparation in renal transplant recipients. Ther Drug Monit 2013; 35: 228-32.

18. Kikuchi M, Tanaka M, Takasaki S, Takahashi A, Akiba M, Matsuda Y, Noda M, Hisamichi K, Yamaguchi H, Okada Y, Mano N. Comparison of PETINIA and LC-MS/MS for determining plasma mycophenolic acid concentrations in Japanese lung transplant recipients. J Pharm Health Care Sci. 2018;
$4: 7$.

19. van Gelder T, Klupp J, Barten MJ, Christians U, Morris RE. Comparison of the effects of tacrolimus and cyclosporine on the pharmacokinetics of mycophenolic acid. Ther Drug Monit 2001; 23: 119128.

20. Hesselink DA, van Hest RM, Mathot RA, Bonthuis $\mathrm{F}$, Weimar $\mathrm{W}$, de Bruin RW, van Gelder $\mathrm{T}$. Cyclosporine interacts with mycophenolic acid by inhibiting the multidrug resistance-associated protein 2. Am J Transplant 2005; 5: 987-994.

21. Cremers S, Schoemaker R, Scholten E, den Hartigh J, König-Quartel J, van Kan E, Paul L, de Fijter J. Characterizing the role of enterohepatic recycling in the interactions between mycophenolate mofetil and calcineurin inhibitors in renal transplant patients by pharmacokinetic modelling. Br J Clin Pharmacol 2005; 60: 249-256.

22. Park JM, Lake KD, Cibrik DM. Impact of changing from cyclosporine to tacrolimus on pharmacokinetics of mycophenolic acid in renal transplant recipients with diabetes. Ther Drug Monit 2008; 30: 591-596.

23. Ting LS, Partovi N, Levy RD, Riggs KW, Ensom MH. Pharmacokinetics of mycophenolic acid and its phenolic-glucuronide and ACY1 glucuronide metabolites in stable thoracic transplant recipients. Ther Drug Monit 2008; 30: 282-291.

24. Kofler S, Deutsch MA, Bigdeli AK, Shvets N, Vogeser M, Mueller TH, Meiser B, Steinbeck G, Reichart B, Kaczmarek I (2009) Proton pump inhibitor co-medication reduces mycophenolate acid drug exposure in heart transplant recipients. J Heart Lung Transplant 28: 605-11.

25. Bullingham R, Shah J, Goldblum R, Schiff M (1996) Effects of food and antacid on the pharmacokinetics of single doses of mycophenolate mofetil in rheumatoid arthritis patients. Br J Clin Pharmacol 41: 513-6.

26. Kodawara T, Masuda S, Yano Y, Matsubara K, Nakamura T, Masada M (2014) Inhibitory effect of ciprofloxacin on $\beta$-glucuronidase-mediated deconjugation of mycophenolic acid glucuronide. Biopharm Drug Dispos 35: 275-83.

27. Bernard O, Tojcic J, Journault K, Perusse L, Guillemette $\mathrm{C}$. Influence of nonsynonymous polymorphisms of UGT1A8 and UGT2B7 metabolizing enzymes on the formation of phenolic and acyl glucuronides of mycophenolic acid. Drug Metab Dispos. 2006; 34: 1539-45.

28. Tett SE, Saint-Marcoux F, Staatz CE, Brunet M, Vinks AA, Miura M, Marquet P, Kuypers DR, van Gelder T, Cattaneo D. Mycophenolate, clinical 
pharmacokinetics, formulations, and methods for assessing drug exposure. Transplant Rev (Orlando). 2011; 25: 47-57.

29. Ting LS, Partovi N, Levy RD, Riggs KW, Ensom MH. Pharmacokinetics of mycophenolic acid and its glucuronidated metabolites in stable lung transplant recipients. Ann Pharmacother 2006; 40: 1509-1516.

30. Bruchet NK, Ensom MH. Limited sampling strategies for mycophenolic acid in solid organ transplantation: a systematic review. Expert Opin Drug Metab Toxicol 2009; 5: 1079-97.

31. Zhang J, Sun Z, Zhu Z, Yang J, Kang J, Feng G, Zhou L, Zuo L, Luo Y, Zhang X. Pharmacokinetics of Mycophenolate Mofetil and Development of Limited Sampling Strategy in Early Kidney Transplant Recipients. Front Pharmacol 2018; 9: 908.

32. Fan Y, Xiao YB, Weng YG. Tacrolimus versus cyclosporine for adult lung transplant recipients: a meta-analysis. Transplantation Proceedings 2009; 41: 1821-1824.

33. Penninga L, Penninga EI, Møller CH, Iversen M, Steinbrüchel DA, Gluud C. Tacrolimus versus cyclosporin as primary immunosuppression for lung transplant recipients. Cochrane Database Syst Rev 2013; 31: Cd008817. 